Canadian

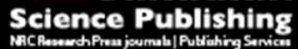

Canadian Journal of Physiology and Pharmacology Revue canadienne de physiologie et pharmacologie

\title{
Vascular senescence and ageing: a role for the MEOX proteins in promoting endothelial dysfunction.
}

\begin{tabular}{|r|l|}
\hline Journal: & Canadian Journal of Physiology and Pharmacology \\
\hline Manuscript ID & cjpp-2017-0149.R1 \\
\hline Danuscript Type: & Review \\
\hline $\begin{array}{r}\text { Complete List of Authors: } \\
\text { Is the invited manuscript for } \\
\text { consideration in a Special } \\
\text { Issue?: }\end{array}$ & $\begin{array}{l}\text { Northcott, Josette ; University of Manitoba College of Medicine } \\
\text { Czubryt, Michael; University of Manitoba, Department of Physiology and } \\
\text { Wigle, Jeffrey; St. Boniface Hospital Research Centre, }\end{array}$ \\
\hline Keyword: & Meox2, p53, ageing, senescence, endothelial cells \\
\hline \multicolumn{2}{|c}{} \\
\hline
\end{tabular}

\section{SCHOLARONE \\ Manuscripts}




\section{Vascular senescence and ageing: a role for the MEOX proteins in promoting endothelial}

\section{dysfunction.}

Josette M. Northcott ${ }^{1,2}$ Michael P. Czubryt ${ }^{1,3}$ and Jeffrey T. Wigle ${ }^{1,2^{*}}$

${ }^{1}$ Institute of Cardiovascular Sciences, St. Boniface Albrechtsen Research Centre, Winnipeg, Canada

${ }^{2}$ Department of Biochemistry and Medical Genetics, Max Rady College of Medicine, Rady Faculty of Health Sciences, University of Manitoba, Winnipeg, Canada

3 Department of Physiology and Pathophysiology, Max Rady College of Medicine, Rady Faculty of Health Sciences, University of Manitoba, Winnipeg, Canada

${ }^{*}$ Corresponding author

jwigle@sbrc.ca 


\begin{abstract}
In the vascular system, ageing is accompanied by the accrual of senescent cells and is associated with an increased risk of vascular disease. Endothelial cell (EC) dysfunction is a hallmark of vascular disease and is characterized by decreased angiogenic potential, reduced nitric oxide bioavailability, impaired vasodilation, increased production of ROS and enhanced inflammation. In ECs, the major producer of nitric oxide is the endothelial nitric oxide synthase (eNOS) enzyme that is encoded by the NOS3 gene. NOS3/eNOS function is tightly regulated at both the transcriptional and post-transcriptional levels in order to maintain normal vascular function. A key transcriptional regulator of eNOS expression is $\mathrm{p} 53$, which has been shown to play a central role in mediating cellular senescence and thereby vascular dysfunction. Herein, we show that in ECs the MEOX homeodomain transcription factors decrease the expression of genes involved in angiogenesis, repress eNOS expression at the mRNA and protein levels and increase the expression of $p 53$. These findings support a role for the MEOX proteins in promoting endothelial dysfunction.
\end{abstract}

\title{
Keywords
}

Endothelial cells, ageing, progeria, senescence, nitric oxide synthase, transcription, p53, MEOX2. 


\section{Introduction}

Ageing is accompanied by the progressive loss of tissue homeostasis and gradual organ deterioration. Vascular physiology must be carefully regulated in order to meet the changing metabolic needs of the body and to prevent the development of diseases, which arise from aberrant repair and structural remodeling of blood vessels (Carmeliet 2003). Vascular function declines with age and diseases including cardiovascular (e.g., atherosclerosis and myocardial infarction), cerebrovascular (e.g., stroke) and peripheral vascular diseases (e.g., limb ischemia) are the leading cause of death worldwide (Mackay 2004). While there are many risk factors for developing vascular disease (e.g., smoking, obesity, hypertension and diabetes), the primary risk factor for the development and progression of vascular disease is age.

Given the widespread distribution of the vasculature throughout the body, it is not surprising that the pathogenesis of many age-related diseases (e.g. diabetic retinopathy, Alzheimer's disease (AD)) involve vascular pathologies (Carmeliet 2003). Furthermore, genetic disorders of accelerated ageing, such as Hutchinson-Gilford progeria syndrome (HGPS) and Werner syndrome, are characterized by the accelerated development of vascular disease (Navarro et al. 2006). Indeed, much of what is currently known about the cellular processes that cause age-related pathologies has been discovered through studying these rare genetic diseases.

In this review, we discuss the cellular processes underlying the development of vascular disease (Figure 1) both during natural ageing and in the accelerated ageing syndromes, with emphasis on the changes occurring within the endothelium. We also examine the role of p53 in these processes and present new data that links MEOX2 homeodomain transcription factor with p53 expression, endothelial dysfunction and senescence. 


\section{Processes underlying vascular ageing and development of disease}

\section{Senescence}

Cellular senescence (a state of permanent cell cycle arrest) was first postulated by Leonard Hayflick in the 1960 s to explain the limited proliferation capacity of normal diploid human fibroblasts in vitro (Hayflick 1965; Hayflick and Moorhead 1961). Since then, senescence has been demonstrated to occur in ageing tissues in vivo. Senescence can be induced by many different stimuli that can be divided into two broad categories: replicative senescence (RS) and stress-induced premature senescence (SIPS) (Erusalimsky 2009). Replicative senescence is associated with telomere shortening (Bodnar et al. 1998; Hastings et al. 2004), whereas stress-induced premature senescence is independent of telomere shortening. Examples of cellular stresses that can induce premature senescence include DNA damage, oxidative stress and oncogene activation (e.g. Harvey rat sarcoma viral oncogene homolog (HRAS) over-expression) (Campisi and d'Adda di Fagagna 2007; Moiseeva et al. 2006; Serrano et al. 1997). There are only a few well accepted markers of cellular senescence including augmented expression and activation of $\mathrm{p} 53$, increased expression of the $\mathrm{p} 21^{\mathrm{CIP} 1 / \text { WAF1 }}$ and p16 ${ }^{\text {INK4a }}$ cell cycle regulators (Campisi and d'Adda di Fagagna 2007; Krishnamurthy et al. 2004), heterochromatic foci formation (Narita et al. 2003), nuclear promyelocytic leukemia (PML) protein aggregation (Ferbeyre et al. 2000) and senescence-associated $\beta$-galactosidase (SA- $\beta$-gal) expression (Dimri et al. 1995). However, none of these markers are entirely specific to senescence and none are a feature of all forms of senescence (Campisi and d'Adda di Fagagna 2007), therefore subsets of these markers are often used to detect and measure senescence. 


\section{Endothelial dysfunction}

As blood vessels age, they accumulate increasing numbers of senescent cells. Endothelial senescence results in endothelial cell (EC) dysfunction that promotes atherosclerotic vascular disease (Erusalimsky 2009). Human blood vessels that contain atherosclerotic plaques have a higher proportion of senescent vascular smooth muscle cells (VSMCs) and ECs, as compared to disease-free vessels (Minamino et al. 2002; Minamino et al. 2003; Vasile et al. 2001). Senescent ECs have reduced eNOS expression (Hoffmann et al. 2001; Matsushita et al. 2001; Sato et al. 1993), impaired angiogenic and repair capability (Uraoka et al. 2011) and altered metabolism that result in endothelial dysfunction and the progression of vascular disease (Erusalimsky and Kurz 2005; Foreman and Tang 2003).

EC dysfunction, a major hallmark of vascular disease, results from a combination of metabolic and gene expression changes that leads to decreased angiogenic potential and nitric oxide (NO) production, as well as increased expression of pro-inflammatory and pro-thrombotic mediators (Cooke 2000; Davignon and Ganz 2004; Deanfield et al. 2007). Acute injury and chronic stress of ECs over time leads to changes in gene expression, which underlie EC dysfunction (Blann 2003; Thum et al. 2000). With advancing age, accumulation of damage to ECs causes EC dysfunction and this proinflammatory state further exacerbates damage to ECs and promotes the development and progression of vascular diseases such as atherosclerosis, hypertension and stroke (Blann 2003).

Endothelial dysfunction is primarily characterized by the loss of NO bioavailability in the endothelium, which results in decreased vasodilation as a consequence of reduced VSMC relaxation (Davignon and Ganz 2004). Aged vasculature has weakened vasodilatory responses and increased vascular stiffness (Kovacic et al. 2011). Impaired vasorelaxation promotes hypertension and is predictive of future adverse cardiovascular events, such as myocardial infarction and stroke (Davignon 
and Ganz 2004; Deanfield et al. 2007). Loss of the endothelial NO production triggers VSMC proliferation and migration leading to vessel stenosis. In addition to its essential role in mediating vasorelaxation, constitutive production of $\mathrm{NO}$ by the endothelium is also critical for controlling blood coagulation (inhibits platelet aggregation), inflammation (prevents leukocyte adhesion to the endothelium) and maintenance of the endothelial progenitor cell population (Aird 2007).

In ECs, the major producer of NO is the endothelial nitric oxide synthase (eNOS) enzyme, which is encoded by the nitric oxide synthase 3 (NOS3) gene. NOS3/eNOS knockout mice develop hypertension and are susceptible to thrombosis, stroke and atherosclerosis (Godecke et al. 1998; Huang et al. 1995; Shesely et al. 1996). The eNOS enzyme converts L-arginine and molecular oxygen into L-citrulline and NO (Kolluru et al. 2010; Qian and Fulton 2013). NO production is dependent upon both the level of expression and the enzymatic activity of eNOS (Kolluru et al. 2010; Qian and Fulton 2013; Tai et al. 2004). The expression of the NOS3 gene is regulated at the epigenetic, transcriptional and post-transcriptional levels (Tai et al. 2004). Several transcription factors have been shown to activate NOS3 transcription, including SP1, SP3, ETS1, NFKB and EER $\alpha 1$ (Davis et al. 2004; KarantzoulisFegaras et al. 1999; Sumi and Ignarro 2003). In contrast, only MAZ, FOXO1 and FOXO3a have been shown to repress NOS3 transcription (Karantzoulis-Fegaras et al. 1999; Potente et al. 2005). The enzymatic activity of eNOS is controlled by a combination of phosphorylation, localization, proteinprotein interactions and cofactor availability (Kolluru et al. 2010; Qian and Fulton 2013). In the absence of its cofactor $\mathrm{BH} 4$, eNOS becomes uncoupled and produces the reactive superoxide anion (Kolluru et al. 2010).

Furthermore, reactive oxygen species (ROS) such as the superoxide anion react with NO producing peroxynitrite, further reducing the amount of bioavailable NO (Kolluru et al. 2010). Enhanced ROS production, decreased proliferative capacity and increased expression of pro- 
thrombotic (e.g. endothelin-1, plasminogen activator inhibitor-1) and pro-inflammatory (e.g. ICAM-1, VCAM-1, E-selectin) mediators are also features of EC dysfunction (Davignon and Ganz 2004; Deanfield et al. 2007). Moreover, both increased ROS and loss of NO induce cellular senescence (Deanfield et al. 2007; Erusalimsky 2009; Lee et al. 1999). EC senescence causes endothelial dysfunction and thereby promotes vascular disease (Erusalimsky and Kurz 2005; Foreman and Tang 2003). Thus, factors that negatively influence eNOS transcription and phosphorylation or augment ROS production promote endothelial dysfunction.

\section{Oxidative stress and DNA damage}

EC ageing is accompanied by the progressive accumulation of oxidative damage to cellular components such as DNA and proteins (Donato et al. 2015). Oxidative damage occurs when ROS react with these molecules and alters their function. The majority of cellular ROS is produced by mitochondrial respiration, however, ROS can also be generated from eNOS uncoupling (Kolluru et al. 2010). ROS-induced DNA damage can cause stress-induced cellular senescence via activation of the p53 pathway (Donato et al. 2015; Rufini et al. 2013).

\section{Accelerated ageing syndromes with vascular disease}

During natural vascular ageing, blood vessels undergo many molecular, functional and structural changes. In addition to endothelial dysfunction, arterial vessels display increased medial thickening and stiffness as a result of enhanced collagen deposition, destruction of the elastic extracellular matrix networks and augmented VSMC proliferation (Kovacic et al. 2011). Similar to natural ageing, some progeroid syndromes (genetic disorders characterized by features of accelerated ageing) display vascular changes that manifest into life threatening vascular disease (Ikeda et al. 2016). HGPS and Werner Syndrome are the progeroid syndromes that most closely resemble natural 
ageing and that are typified by vascular pathologies (Ikeda et al. 2016). These syndromes arise from single-gene mutations that perturb nuclear structure or DNA repair, respectively, ultimately resulting in genomic instability (Ikeda et al. 2016).

\section{Hutchinson-Gilford progeria syndrome}

HGPS is a rare genetic disorder of accelerated ageing caused by mutations in the Lamin A (LMNA) gene (De Sandre-Giovannoli et al. 2003; Eriksson et al. 2003). The classical LMNA mutation at codon $608(\mathrm{G}>\mathrm{G})$ does not affect protein coding, but instead causes alternative splicing of the LNMA transcript that results in the production of a truncated pre-Lamin A protein (known as 'progerin' and 'Lamin A- $\Delta 50^{\prime}$ )(Eriksson et al. 2003; Ikeda et al. 2016). The mutant pre-Lamin A, which lacks a ZMPSTE24 cleavage site, cannot be properly post-translationally processed and consequently, remains farnesylated and nuclear membrane-bound (Ikeda et al. 2016; Navarro et al. 2006). Accumulation of progerin leads to nuclear structure changes including membrane blebs and altered chromatin organization (Ikeda et al. 2016; Navarro et al. 2006).

Children with HGPS are diagnosed by a mean age of 3 and have a life expectancy of approximately 13 years of age (Navarro et al. 2006). These individuals most often succumb to myocardial infarctions or strokes that are caused by accelerated atherosclerosis (Ikeda et al. 2016; Navarro et al. 2006). While the abundance of atherosclerotic plaque and vascular calcification within the aorta and coronary arteries of individuals with HGPS is variable, the phenotype of these plaques is similar to those observed in the arteries of elderly individuals. However, one notable difference between naturally aged elderly vessels and those from HGPS individuals is the absence of medial thickening in HGPS arteries, presumably due to an increased sensitivity to mechanical strain that reduces VSMCs viability (Varga et al. 2006; Verstraeten et al. 2008). At the molecular level, cells from 
HGPS individuals also have shorter telomeres than non-affected individuals (Alter et al. 2007; Decker et al. 2009).

Mouse models with either mutation of Lmna, or knockout of Zmpste24, experience accelerated ageing (Koks et al. 2016; Varela et al. 2005). However, cardiovascular disease that recapitulates the loss of VSMCs and increased fibrosis observed in individuals with HGPS has only been reported in mice carrying a bacterial artificial chromosome encoding the G608G mutant form of LMNA (Varga et al. 2006). While vascular dysfunction in $Z m p s t e 24^{-/}$mice has not been reported, these mice develop dilated cardiomyopathy (Pendas et al. 2002), which suggests the possibility of underlying vascular dysfunction. In cells from Zmpste24 deficient mice, accumulation of mutant prelamin A results in the activation of p53 and cellular senescence (Varela et al. 2005). This may recapitulate the role of p53 in senescence during natural ageing, as nuclear accumulation of progerin has been demonstrated in cells obtained from elderly individuals (McClintock et al. 2007).

\section{Werner syndrome}

Werner syndrome is another genetic disorder of accelerated ageing in which affected individuals develop cardiovascular disease. This disorder is caused by mutations in the WRN gene, which encodes a DNA helicase required for both single and double-strand DNA break repair pathways and results in the loss of genomic integrity (Ikeda et al. 2016; Navarro et al. 2006). The mean age of diagnosis for individuals with Werner syndrome is 24 years and their average life expectancy is 47 years of age (Navarro et al. 2006). Not unlike natural ageing, the most common causes of mortality for individuals with Werner syndrome are atherosclerotic cardiovascular disease and cancer (Ikeda et al. 2016; Navarro et al. 2006). At the cellular level, inhibition of the 53 pathway is observed in cells derived from individuals with Werner syndrome (Blander et al. 1999; Spillare et al. 1999). Thus, the 
concomitant increase in genomic instability and decreased capacity for p53-induced senescence explains why people with Werner syndrome are at increased risk for developing cancer.

Interestingly, while Wrn knockout mice do not display phenotypes of accelerated ageing (Lombard et al. 2000), combined knockout of Wrn and Terc (the RNA component of the telomerase enzyme) recapitulates the features of Werner syndrome in humans (Chang et al. 2004). To date, vascular alterations have yet to be described in these mouse models.

\section{Other mouse models of ageing-related vascular dysfunction}

In addition to the aforementioned mouse models, there exists several other genetically modified mouse strains that have shown potential utility for the study of vascular disease and ageing (Harkema et al. 2016; Koks et al. 2016). While the relatively short lifespan of mice permits the study of ageing, unlike humans, mice have much longer telomeres and do not have a propensity for the development of atherosclerotic vascular disease (Calado and Dumitriu 2013; Russell and Proctor 2006). Despite these limitations, mouse models have been instrumental in expanding our understanding of ageing and cardiovascular disease, as described below.

The senescence-prone inbred mouse strain (SAMP8) develops premature ageing-related endothelial dysfunction at 6 months of age, which correlates with a loss of eNOS expression in the aorta (Novella et al. 2013). Furthermore, ECs of cerebral microvessels from SAMP8 mice display increased senescence and reduced SIRT1 expression as compared to the senescence-resistant (SAMR1) mouse strain (Ota et al. 2012). Not surprisingly, by 6 months SAMP8 mice develop more severe perivascular cardiac fibrosis and diastolic dysfunction than the SAMR1 controls (Reed et al. 2011).

The Colla1 ${ }^{(\mathrm{r} / \mathrm{r})}$ mouse model which produces collagenase-resistant collagen undergoes accelerated ageing (Vafaie et al. 2014). These mice develop hypertension and display increased stress- 
induced vascular cell senescence, characterized by the up-regulation of $\mathrm{p} 21^{\mathrm{CIP} 1 / \text { WAF1 }}$ and $\mathrm{p} 16^{\text {INK4A }}$ expression, in response to angiotensin II perfusion (Vafaie et al. 2014).

Transgenic mice with a hypomorphic mutation in the $B u b 1 b$ gene $\left(B u b 1 b^{H / H}\right)$ express reduced levels of the Bub1b mitotic checkpoint protein. These mice display features of accelerated ageing, including vasculature changes (Baker et al. 2004). By mature adulthood (3-5 months of age), thinning of the aortic wall with fewer VSMCs, increased fibrosis and decreased compliance is already apparent in $B u b 1 b^{H / H}$ mice (Matsumoto et al. 2007). Furthermore endothelial dysfunction, as defined by impaired endothelium-dependent relaxation, decreased NOS enzyme activity and increased ROS production is also apparent (Matsumoto et al. 2007). Loss of Bub1b expression occurs normally in aged ( 1 year old) wild-type mice, suggesting that the phenotype in these mice may be an accurate reflection of the natural ageing process.

$\operatorname{Ercc1}^{-/ \Delta}$ mice carry mutations that impede the nucleotide-excision DNA repair pathway and are models of accelerated ageing that display age-related vascular dysfunction (Dolle et al. 2011; Weeda et al. 1997). These mice develop hypertension and age-related impairment in endothelial dependent relaxation (Durik et al. 2012). In addition, $\operatorname{Ercc1}^{-/ \Delta}$ mice have accelerated loss of corneal ECs, a characteristic of natural ageing (Roh et al. 2013).

The ApoE-deficient mouse is the most well-defined and commonly used model of atherosclerosis (Meyrelles et al. 2011; Vasquez et al. 2012). The ApoE gene is involved in lipid metabolism and knockout mice have chronic hypercholesterolemia and develop atherosclerotic lesions that are pathologically similar to the human disease (Vasquez et al. 2012). These mice exhibit endothelial dysfunction (impaired NO-dependent vasorelaxation) and increased vascular senescence with ageing (Meyrelles et al. 2011). When ApoE-deficiency was combined with eNOS knockout and a 
high-fat diet, the atherosclerotic phenotype was exacerbated, leading to coronary artery disease and vascular aneurysms (Kuhlencordt et al. 2001).

The link between p53 and ageing was demonstrated by studies using p53 mutant mice which display accelerated ageing phenotypes (Maier et al. 2004; Tyner et al. 2002). Interestingly, while knockout of p53 in the ApoE-deficient mouse model accelerated atherosclerosis (Guevara et al. 1999), increased expression of p53 in the ApoE model was not protective against atherosclerosis (SanzGonzalez et al. 2007).

Mouse models are important contributors to our understanding of the mechanisms underlying vascular dysfunction. By combining two or more genetic models, much can be learned about the complex interplay between different cellular processes and how they affect the vascular system overall.

\section{Role of p53 and SIRT1 in regulating senescence of the vasculature}

The $\mathrm{p} 53$ protein functions as a tumour suppressor and it has been determined to be deleted or mutated in at least half of human cancers (Hollstein et al. 1991). Activation of p53 can be triggered by both replicative stress (shortened telomeres) and by DNA damage. During ageing, stresses such as hyperglycemia, smoking and turbulent flow can increase the levels of ROS in ECs, which can cause DNA damage and thereby activate p53 (Warboys et al. 2014). Activation of p53 and induction of its downstream target $\mathrm{p} 21^{\mathrm{CIP1} / \mathrm{WAF} 1}$ are hallmarks of senescence.

The function of p53 is dynamically controlled by post-translational modifications such as phosphorylation and acetylation (Appella and Anderson 2000). Acetylation activates p53 and turns it into a more potent transcriptional regulator (Figure 2). Acetylation of $p 53$ is controlled by a balance between acetyl transferases and deacetylases (Gu et al. 1997; Luo et al. 2001). A deacetylase that 
targets p53 is SIRT1 (Luo et al. 2001). The yeast ortholog of SIRT1, Sir2, was discovered to regulate lifespan in yeast in response to caloric restriction (Lin et al. 2002). SIRT1 was also shown to be a target of the polyphenol resveratrol (Howitz et al. 2003). An early study by Ota and colleagues demonstrated that SIRT1 was critical for preventing endothelial dysfunction induced by oxidative stress and this correlated with decreased p53 acetylation (Ota et al. 2007). Subsequent studies showed that SIRT1 activation protected against hyperglycemia induced endothelial dysfunction both in vitro and in vivo (Chen, H et al. 2012; Orimo et al. 2009). Interestingly, hyperglycemia reduced lifespan in wild-type EC but not in EC that were null for p53 (Orimo et al. 2009). A recent study demonstrated that turbulent blood flow, a risk factor for development of atherosclerotic plaques, induced endothelial senescence via a p53 dependent pathway and that this process could be blocked by treatment with a SIRT1 activator (Warboys et al. 2014). In addition, endothelial senescence in the spontaneously hypertensive rat model was decreased with treatment with a SIRT1 activator. This treatment correlated with a decrease in p53 acetylation and increased NOS3 transcription (Han et al. 2012). Regulation of p53 by SIRT1 is important for the control of cellular senescence in many different tissues including the endothelium (Saunders and Verdin 2007) (Figure 2).

\section{Negative regulation of eNOS by $\mathrm{p} 53$}

In ECs, eNOS is negatively regulated by $\mathrm{p} 53$. While, the NOS3 promoter contains a functional p53 binding site (Mortensen et al. 1999), direct transcriptional repression of the NOS3 promoter by p53 has not been demonstrated in ECs. However, p53 was shown to indirectly suppress NOS3 transcription in human umbilical vein endothelial cells (HUVECs) by repressing the expression of KLF2, a direct transactivator of the NOS3 gene (Kumar et al. 2011). Furthermore, over-expression of p53 in the endothelium of mice was shown to negatively regulate eNOS activation by inhibiting its phosphorylation by Akt (Yokoyama et al. 2014). In this latter study, the authors did not observe down- 
regulation of eNOS expression in response to p53 over-expression, suggesting that either p53 regulation of eNOS may be species-specific or it may be altered by cellular context.

\section{Mesenchyme homeobox2}

The mesenchyme homeobox genes, MEOX1 and MEOX2, encode a family of homeodomain transcription factors. The MEOX proteins are involved in the proper formation of muscle and bone during embryonic development (Bayrakli et al. 2013; Mankoo et al. 2003) and are important regulators of vascular function in the adult (Gorski and Leal 2003; Gorski et al. 1993; Wu et al. 2005). The MEOX homeodomain transcription factors share a highly conserved homeodomain and partial functional redundancy exists between MEOX1 and MEOX2 during development (Mankoo et al. 2003), suggesting that these proteins regulate the transcription of many common target genes and may also share similar roles in the vasculature. In spite of this, the role of MEOX1 in the vasculature is not well defined.

In the adult vasculature, MEOX2 is expressed in VSMCs and ECs where it inhibits proliferation and induces apoptosis (Maillard et al. 1997; Perlman et al. 1999; Perlman et al. 1998; Smith et al. 1997; Wu et al. 2005). In rat VSMCs, the expression of MEOX2 mRNA is down-regulated in vitro in response to serum and growth factors, as well as in vivo in response to vascular injury (Gorski et al. 1993; Markmann et al. 2003; Weir et al. 1995). Over-expression of MEOX2 in VSMCs inhibits cell proliferation (Maillard et al. 1997; Smith et al. 1997). This inhibition is due to MEOX2-induced transcriptional up-regulation of the cyclin-dependent kinase (CDK) inhibitor p21 ${ }^{\text {CIP1/WAF1 }}$, decreased CDK2 activity and subsequent cell cycle block in the G1 phase (Smith et al. 1997). Up-regulation of p21 $1^{\text {CIP1/WAF1 }}$ expression by MEOX2 was shown to be independent of $p 53$, as MEOX2 was able to increase $\mathrm{p} 21^{\mathrm{CIP1} / \mathrm{WAF} 1}$ transcription and inhibit cell proliferation in p53 deficient mouse embryonic 
fibroblasts (Smith et al. 1997). MEOX2 over-expression also prevents VSMC migration in response to growth factors (Witzenbichler et al. 1999).

Similarly, MEOX2 over-expression in ECs increases p21 $1^{\text {CIP1/WAF1 }}$ expression and decreases cell proliferation and migration (Chen, Y et al. 2007; Gorski and Leal 2003; Patel et al. 2005). Furthermore, MEOX2 modulates EC network formation in vitro and angiogenesis in vivo, in a dose dependent manner, where both over-expression and knockdown of MEOX2 inhibit the formation of new vessel structures by ECs (Gorski and Leal 2003; Patel et al. 2005; Wu et al. 2005). In endothelial colony forming cells (ECFCs; adult tissue-resident endothelial progenitor cells), ectopic expression of MEOX2 delays cell cycle progression in G1 and induces senescence; however, remarkably MEOX2 expression also increases ECFC migration and enhances network formation in these cells (Gohn et al. 2016).

We have previously shown that the MEOX proteins activate transcription of the cell cycle inhibitors $\mathrm{p} 21^{\mathrm{CIP1} / \mathrm{WAF} 1}$ and $\mathrm{p} 16^{\mathrm{INK} 4 a}$, as well as induce endothelial senescence (Douville et al. 2011). Due to the rapid induction of senescence by the MEOX proteins (within 48 hours), we believe that MEOX induced senescence is a form of stress-induced premature senescence. However, as we have not assessed changes in telomere length or uncapping, we cannot formally discount the possibility that MEOX induced senescence may be a form of accelerated replicative senescence.

Altered MEOX2 gene expression has been documented in a number of human diseases including HGPS, hepatic portal hypertension, $A D$ and cancer, all of which have perturbed vascular function (Csoka et al. 2004; Wu et al. 2005; Zeng et al. 2006). Recently, a combination of sequence variations (SNP haplotype) within the non-coding regions of the MEOX2 gene were shown to be predictive of coronary heart disease (Yang et al. 2015); however, the molecular mechanisms for this association are currently unknown. As a transcription factor, MEOX2 has the potential to control the 
expression of many target genes and thereby modify vascular cell phenotype and function (Douville and Wigle 2007).

\section{MEOX2 in Alzheimer's disease}

Hallmarks of $A D$ include decreased cerebral microvasculature and accumulation of neurotoxic Amyloid- $\beta$ in the brain (Deane and Zlokovic 2007). MEOX2 expression is decreased in human brain ECs from $A D$ individuals and these ECs have reduced tube formation capability and augmented levels of apoptosis as compared to age matched controls (Wu et al. 2005). Knockdown of MEOX2 in normal human brain ECs recapitulates the defects in tube formation and increased apoptosis observed in the brain ECs derived from individuals with AD (Wu et al. 2005). Furthermore, restoration of MEOX2 expression in AD brain ECs increases tube formation (Wu et al. 2005).

Heterozygous Meox2 gene knockout mice $\left(\right.$ Meox $2^{+/-}$) have cerebrovascular defects including decreased cerebral blood flow, decreased cerebral capillary density and decreased cerebral angiogenesis in response to hypoxia (Wu et al. 2005). Brain ECs from Meox $2^{+/-}$mice have increased pro-apoptotic FOXO4 protein expression, decreased anti-apoptotic BCL2L1 protein expression and decreased tube formation capabilities (Wu et al. 2005), which is consistent with increased apoptosis and decreased cerebrovasculature. In addition, Meox $2^{+/-}$mice have increased Amyloid- $\beta$ retention in the brain due to decreased clearance across the blood brain barrier (Wu et al. 2005). Expression of the mature form of low density lipoprotein receptor-related protein 1 (LRP1), the major amyloid- $\beta$ clearance receptor at the blood-brain barrier, is decreased in brain ECs of Meox $2^{+/-}$mice and following knockdown of MEOX2 in normal brain ECs (Wu et al. 2005). This was found to be due to decreased expression of LRP associated protein 1 (LRPAP1), a chaperone required for the proper folding of mature LRP1. Knockdown of MEOX2 in normal human brain ECs decreases LRPAP1 mRNA and protein expression (Wu et al. 2005), suggesting that LRPAP1 is a direct transcriptional target of MEOX2 
transactivation. When crossed with a mouse model of $A D$ (B6.APB ${ }^{\top g}$ mice), Meox2 haploinsufficiency exacerbates neuronal cell loss (Soto et al. 2016).

An analysis of copy number variation in autosomal dominant early-onset AD individuals identified a duplication of a genomic region that includes the upstream promoter region and exon 1 of the MEOX2 gene (Rovelet-Lecrux et al. 2012). Changes in MEOX2 transcription level were not assessed, but the authors hypothesized that disruption of the regulatory region is likely to reduce MEOX2 function (Rovelet-Lecrux et al. 2012).

\section{MEOX2 in HGPS}

Microarray analysis has shown that MEOX2 expression is significantly increased in cells from HGPS patients (Csoka et al. 2004; Plasilova et al. 2011). Csoka and colleagues compared gene expression profiles of dermal fibroblasts from HGPS individuals that were heterozygous for the classical LMNA GGC>GGT mutation at codon $608(\mathrm{G}>\mathrm{G})$ to normal age-matched controls using microarray analysis (Csoka et al. 2004). The authors found that MEOX2 mRNA expression was upregulated 29.1-fold in HGPS cells (Csoka et al. 2004). Furthermore, homozygous mutation for the atypical LMNA AAG>AAC mutation at codon $542(\mathrm{~K}>\mathrm{N})$ also causes HGPS and gene expression analysis of dermal fibroblasts revealed a 5.36-fold increase in MEOX2 expression in these cells (Plasilova et al. 2011).

\section{Recent findings}

We postulated that MEOX2 (and potentially MEOX1) may play an active role in atherosclerosis by regulating the transcription of genes that promoting senescence and endothelial dysfunction. In order to identify changes to gene expression networks and cellular functions induced by MEOX protein expression in ECs, mRNA levels were analyzed by microarray. Gene-set enrichment analysis of our microarray results demonstrated that MEOX1 and MEOX2 controlled the expression of a set of 
genes involved in a variety of cellular processes (Figure 3A). The majority of differentially expressed gene-sets in HUVECs ectopically expressing MEOX1 or MEOX2 were common to both MEOX transcription factors. This finding was not surprising given the functional redundancy that exists between MEOX1 and MEOX2 during embryonic development (Mankoo et al. 2003).

Expression of MEOX1 or MEOX2 in HUVECs resulted in the coordinated increases in the mRNA level of genes involved in lysosomal degradation, fatty acid oxidation and carbohydrate metabolism (Figure 3A). Indeed, a recent study by Coppiello and colleagues demonstrated that Meox2 (along with its transcription co-factor Tcf15/paraxis) mediates fatty acid uptake in cardiac ECs (Coppiello et al. 2015). Furthermore, consistent with MEOX-induced senescence, the expression of lysosomal $\beta$ galactosidase was significantly elevated and we have previously shown that senescence associated $\beta$ galactosidase is increased in HUVECs following MEOX1 or MEOX2 transduction (Douville et al. 2011).

We also observed coordinated decreases in genes associated with angiogenesis, positive cell cycle regulation and pseudouridine synthesis (Figure 3A, 3B). Inhibition of RNA pseudouridylation can decrease ribosome biogenesis, mRNA splicing and telomerase activity, leading to cell cycle arrest and premature senescence (Meier 2005). In fact, two of the genes identified as being significantly changed in our array are DKC1 and NOP10, which are components of the telomerase complex and are mutated in Dyskeratosis Congenita, a premature ageing syndrome (Mitchell et al. 1999; Pogacic et al. 2000). Thus, it is plausible that MEOX proteins may also be involved in telomere maintenance and accelerated replicative senescence.

Within the enriched gene-sets, direct transcriptional targets were identified by focusing on the genes that were not affected by the expression of a DNA-binding deficient version of MEOX2 $\left(\right.$ MEOX $2^{\text {Q235E }}$ ) (Figure 3B). Senescent ECs have impaired angiogenic capability (Uraoka et al. 2011) and decreased NO production (Hoffmann et al. 2001; Matsushita et al. 2001; Sato et al. 1993), resulting in 
endothelial dysfunction (Erusalimsky and Kurz 2005; Foreman and Tang 2003). Notably, one of the most significantly down-regulated genes in the angiogenesis gene-set was NOS3 (Figure 3A, 3B), which encodes eNOS.

Changes in NOS3 mRNA levels (Figure 3C) induced by the MEOX proteins correlated with changes in eNOS protein expression (Figure 3D). Indeed, expression of either MEOX1 or MEOX2 resulted in decreased eNOS protein levels. Analogous to MEOX2 ${ }^{\mathrm{Q} 235 \mathrm{E}}$, expression of a DNA-binding deficient version of MEOX1 (MEOX1 ${ }^{\mathrm{Q} 219 E}$ ) in HUVECs did not significantly decrease eNOS protein expression. This result suggests that the ability of MEOX proteins to repress NOS3 gene expression requires DNA binding. Furthermore, MEOX2 reduced reporter gene expression from a 1600 bp NOS3 upstream promoter region containing the three putative homeodomain binding sites (data not shown). Direct MEOX2 transcription repression of the NOS3 promoter, was demonstrated by fusing the MEOX2 homeodomain to either the Engrailed repressor or VP16 activator domains (data not shown). This strongly suggests that MEOX2 acts as a direct transcriptional repressor of the NOS3 gene. Interestingly, this is the first report of MEOX proteins acting as transcriptional repressors.

The levels of NO produced by eNOS are regulated by phosphorylation (Kolluru et al. 2010). In ECs, we observed levels of Thr495 (inactive) and Ser1177 (active) phosphorylation that reflected the total abundance of eNOS protein in response to MEOX overexpression in HUVECs (data not shown). While cells may be able to temporarily compensate for decreased NO production by increasing active phosphorylation of eNOS, sustained repression of eNOS transcription will ultimately result in a loss of NO production. Regulation of eNOS by MEOX proteins was conserved in other EC types, namely human aortic endothelial cells (HAECs) (data not shown).

Furthermore, both MEOX1 and MEOX2 overexpression, increase p53 protein levels in ECs (Figure 3E). Augmented p53 protein may not be due to MEOX induced transcription of p53 mRNA, as 
we did not detect any changes in p53 transcript levels by microarray. Thus, MEOX1 and MEOX2, via an unknown mechanism, increase p53 protein synthesis or decrease p53 protein degradation, resulting in higher total cellular levels of p53. As described above, the stability and transcriptional capability of p53 are regulated by a number of post-transcriptional modifications (Boehme and Blattner 2009) thus, future work will assess whether there is an increase in transcriptionally active p53 protein. Additional experiments are needed to elucidate the potential cross-talk that may occur between the MEOX proteins and p53 mediated regulation of the cell cycle.

Together, our previous and current findings support a role for the MEOX transcription factors in enhancing the pathogenesis of atherosclerosis by mediating gene expression changes that result in EC dysfunction. We propose that increased MEOX2 expression in vascular ECs plays an active role in promoting the accelerated atherosclerosis that occurs in individuals with HPGS.

\section{Summary}

Effective prevention and treatment of vascular diseases, necessitates a detailed understanding of the normal physiology of blood vessels and the changes that occur during disease. Although several key signaling pathways have been implicated in mediating the gene expression changes that result in EC dysfunction (Balakumar et al. 2008), many of the direct transcriptional mechanisms that mediate these changes are not well defined. As the phenotype of a cell at any given time is largely determined by its gene expression profile, we can better understand vascular pathologies by studying the molecular events that contribute to EC dysfunction. In this review, we highlighted what is currently known about transcriptional regulators in vascular disease during senescence and ageing and highlighted novel insights into the potential role of the MEOX homeodomain proteins in EC dysfunction. 
Increased expression of the MEOX transcription factors in ECs leads to transcriptional upregulation of the cell cycle inhibitors $\mathrm{p} 21^{\mathrm{CIP} 1 / \mathrm{WAF} 1}$ and $\mathrm{p} 16^{\mathrm{INK} 4 \mathrm{a}}$, cell cycle arrest in the $\mathrm{G} 1$ phase and EC senescence (Douville et al. 2011) (Figure 4). We recently identified eNOS as candidate transcriptional target gene of MEOX1 and MEOX2 in ECs. The expression of eNOS is repressed by MEOX1 and MEOX2, which is expected to reduce NO production and thereby promote vascular dysfunction through increased vasoconstriction and thrombosis (Figure 4). We also observed increased p53 protein levels in ECs expressing MEOX proteins (Figure 4). Together, the existing literature and our recent findings suggest a role for the MEOX transcription factors in enhancing the pathogenesis of atherosclerosis by mediating gene expression changes, which result in EC dysfunction.

Increased MEOX2 expression in vascular EC of children with HGPS is likely to play an active role in promoting the accelerated atherosclerosis that occurs in these individuals. The existence of vascular pathologies associated with both increased (HGPS) and decreased (AD) MEOX2 expression, leads us to reason that the expression of MEOX2 must be tightly regulated for the maintenance of proper EC function. Whether MEOX expression is altered in pre-atherosclerotic lesions of healthy individuals or the vasculature of aged individuals is unknown and is a potential avenue for future studies.

\section{Acknowledgements}

This research was supported by funding from The Canadian Institutes of Health Research, Research Manitoba, St. Boniface Hospital Foundation and the Institute of Cardiovascular Sciences. 


\section{References}

Aird, W.C. 2007. Phenotypic heterogeneity of the endothelium: I. Structure, function, and mechanisms. Circ. Res. 100(2): 158-73. doi:10.1161/01.RES.0000255691.76142.4a. PMID:17272818.

Alter, B.P., Baerlocher, G.M., Savage, S.A., Chanock, S.J., Weksler, B.B., Willner, J.P., et al. 2007. Very short telomere length by flow fluorescence in situ hybridization identifies patients with dyskeratosis congenita. Blood, 110(5): 1439-47. doi:10.1182/blood-2007-02-075598. PMID:17468339.

Appella, E. and Anderson, C.W. 2000. Signaling to p53: breaking the posttranslational modification code. Pathol. Biol. 48(3): 227-45. PMID:10858956.

Baker, D.J., Jeganathan, K.B., Cameron, J.D., Thompson, M., Juneja, S., Kopecka, A., et al. 2004. BubR1 insufficiency causes early onset of aging-associated phenotypes and infertility in mice. Nat. Genet. 36(7): 744-9. doi:10.1038/ng1382. PMID:15208629.

Balakumar, P., Kaur, T. and Singh, M. 2008. Potential target sites to modulate vascular endothelial dysfunction: current perspectives and future directions. Toxicology, 245(1-2): 49-64. doi:10.1016/j.tox.2007.12.011. PMID:18242815.

Bayrakli, F., Guclu, B., Yakicier, C., Balaban, H., Kartal, U., Erguner, B., et al. 2013. Mutation in MEOX1 gene causes a recessive Klippel-Feil syndrome subtype. BMC Genet. 14: 95. doi:10.1186/14712156-14-95. PMID:24073994.

Blander, G., Kipnis, J., Leal, J.F., Yu, C.E., Schellenberg, G.D. and Oren, M. 1999. Physical and functional interaction between p53 and the Werner's syndrome protein. J. Biol. Chem. 274(41): 29463-9. PMID:10506209. 
Blann, A.D. 2003. Assessment of endothelial dysfunction: focus on atherothrombotic disease. Pathophysiol. Haemost. Thromb. 33(5-6): 256-61. doi:83811. PMID:15692226.

Bodnar, A.G., Ouellette, M., Frolkis, M., Holt, S.E., Chiu, C.P., Morin, G.B., et al. 1998. Extension of lifespan by introduction of telomerase into normal human cells. Science, 279(5349): 349-52. PMID:9454332.

Boehme, K.A. and Blattner, C. 2009. Regulation of p53--insights into a complex process. Crit. Rev. Biochem. Mol. Biol. 44(6): 367-92. doi:10.3109/10409230903401507. PMID:19929178.

Calado, R.T. and Dumitriu, B. 2013. Telomere dynamics in mice and humans. Semin. Hematol. 50(2): 165-74. doi:10.1053/j.seminhematol.2013.03.030. PMID:23956466.

Campisi, J. and d'Adda di Fagagna, F. 2007. Cellular senescence: when bad things happen to good cells. Nat. Rev. Mol. Cell Biol. 8(9): 729-40. doi:10.1038/nrm2233. PMID:17667954.

Carmeliet, P. 2003. Angiogenesis in health and disease. Nat. Med. 9(6): 653-60. doi:10.1038/nm0603653. PMID:12778163.

Chang, S., Multani, A.S., Cabrera, N.G., Naylor, M.L., Laud, P., Lombard, D., et al. 2004. Essential role of limiting telomeres in the pathogenesis of Werner syndrome. Nat. Genet. 36(8): 877-82. doi:10.1038/ng1389. PMID:15235603.

Chen, H., Wan, Y., Zhou, S., Lu, Y., Zhang, Z., Zhang, R., et al. 2012. Endothelium-specific SIRT1 overexpression inhibits hyperglycemia-induced upregulation of vascular cell senescence. Sci. China Life Sci. 55(6): 467-73. doi:10.1007/s11427-012-4329-4. PMID:22744176.

Chen, Y., Leal, A.D., Patel, S. and Gorski, D.H. 2007. The homeobox gene GAX activates p21WAF1/CIP1 expression in vascular endothelial cells through direct interaction with upstream AT-rich sequences. J. Biol. Chem. 282(1): 507-17. doi:10.1074/jbc.M606604200. PMID:17074759. 
Cooke, J.P. 2000. The endothelium: a new target for therapy. Vasc. Med. 5(1): 49-53. doi:10.1177/1358836X0000500108. PMID:10737156.

Coppiello, G., Collantes, M., Sirerol-Piquer, M.S., Vandenwijngaert, S., Schoors, S., Swinnen, M., et al. 2015. Meox2/Tcf15 heterodimers program the heart capillary endothelium for cardiac fatty acid uptake. Circulation, 131(9): 815-26. doi:10.1161/CIRCULATIONAHA.114.013721. PMID:25561514.

Csoka, A.B., English, S.B., Simkevich, C.P., Ginzinger, D.G., Butte, A.J., Schatten, G.P., et al. 2004. Genome-scale expression profiling of Hutchinson-Gilford progeria syndrome reveals widespread transcriptional misregulation leading to mesodermal/mesenchymal defects and accelerated atherosclerosis. Aging Cell, 3(4): 235-43. doi:10.1111/j.1474-9728.2004.00105.x. PMID:15268757.

Davignon, J. and Ganz, P. 2004. Role of endothelial dysfunction in atherosclerosis. Circulation, 109(23 Suppl 1): III27-32. doi:10.1161/01.CIR.0000131515.03336.f8. PMID:15198963.

Davis, M.E., Grumbach, I.M., Fukai, T., Cutchins, A. and Harrison, D.G. 2004. Shear stress regulates endothelial nitric-oxide synthase promoter activity through nuclear factor kappaB binding. J. Biol. Chem. 279(1): 163-8. doi:10.1074/jbc.M307528200. PMID:14570928.

De Sandre-Giovannoli, A., Bernard, R., Cau, P., Navarro, C., Amiel, J., Boccaccio, I., et al. 2003. Lamin a truncation in Hutchinson-Gilford progeria. Science, 300(5628): 2055. doi:10.1126/science.1084125. PMID:12702809.

Deane, R. and Zlokovic, B.V. 2007. Role of the blood-brain barrier in the pathogenesis of Alzheimer's disease. Curr. Alzheimer Res. 4(2): 191-7. PMID:17430246.

Deanfield, J.E., Halcox, J.P. and Rabelink, T.J. 2007. Endothelial function and dysfunction: testing and clinical relevance. Circulation, 115(10): 1285-95. doi:10.1161/CIRCULATIONAHA.106.652859. PMID:17353456. 
Decker, M.L., Chavez, E., Vulto, I. and Lansdorp, P.M. 2009. Telomere length in Hutchinson-Gilford progeria syndrome. Mech. Ageing Dev. 130(6): 377-83. doi:10.1016/j.mad.2009.03.001. PMID:19428457.

Dimri, G.P., Lee, X., Basile, G., Acosta, M., Scott, G., Roskelley, C., et al. 1995. A biomarker that identifies senescent human cells in culture and in aging skin in vivo. Proc. Natl. Acad. Sci. U. S. A. 92(20): 9363-7. PMID:7568133.

Dolle, M.E., Kuiper, R.V., Roodbergen, M., Robinson, J., de Vlugt, S., Wijnhoven, S.W., et al. 2011. Broad segmental progeroid changes in short-lived Ercc1(-/Delta7) mice. Pathobiol. Aging AgeRelat. Dis. 1: doi:10.3402/pba.v1i0.7219. PMID:22953029.

Donato, A.J., Morgan, R.G., Walker, A.E. and Lesniewski, L.A. 2015. Cellular and molecular biology of aging endothelial cells. J. Mol. Cell. Cardiol. 89(Pt B): 122-35. doi:10.1016/j.yjmcc.2015.01.021. PMID:25655936.

Douville, J.M. and Wigle, J.T. 2007. Regulation and function of homeodomain proteins in the embryonic and adult vascular systems. Can. J. Physiol. Pharmacol. 85(1): 55-65. doi:10.1139/y06091. PMID:17487245.

Douville, J.M., Cheung, D.Y., Herbert, K.L., Moffatt, T. and Wigle, J.T. 2011. Mechanisms of MEOX1 and MEOX2 regulation of the cyclin dependent kinase inhibitors p21 and p16 in vascular endothelial cells. PLoS One, 6(12): e29099. doi:10.1371/journal.pone.0029099. PMID:22206000.

Durik, M., Kavousi, M., van der Pluijm, I., Isaacs, A., Cheng, C., Verdonk, K., et al. 2012. Nucleotide excision DNA repair is associated with age-related vascular dysfunction. Circulation, 126(4): 46878. doi:10.1161/CIRCULATIONAHA.112.104380. PMID:22705887. 
Eriksson, M., Brown, W.T., Gordon, L.B., Glynn, M.W., Singer, J., Scott, L., et al. 2003. Recurrent de novo point mutations in lamin A cause Hutchinson-Gilford progeria syndrome. Nature, 423(6937): 293-8. doi:10.1038/nature01629. PMID:12714972.

Erusalimsky, J.D. and Kurz, D.J. 2005. Cellular senescence in vivo: its relevance in ageing and cardiovascular disease. Exp. Gerontol. 40(8-9): 634-42. doi:10.1016/j.exger.2005.04.010. PMID:15970413.

Erusalimsky, J.D. 2009. Vascular endothelial senescence: from mechanisms to pathophysiology. J. Appl. Physiol. 106(1): 326-32. doi:10.1152/japplphysiol.91353.2008. PMID:19036896.

Ferbeyre, G., de Stanchina, E., Querido, E., Baptiste, N., Prives, C. and Lowe, S.W. 2000. PML is induced by oncogenic ras and promotes premature senescence. Genes Dev. 14(16): 2015-27. PMID:10950866.

Foreman, K.E. and Tang, J. 2003. Molecular mechanisms of replicative senescence in endothelial cells. Exp. Gerontol. 38(11-12): 1251-7. PMID:14698804.

Godecke, A., Decking, U.K., Ding, Z., Hirchenhain, J., Bidmon, H.J., Godecke, S., et al. 1998. Coronary hemodynamics in endothelial NO synthase knockout mice. Circ. Res. 82(2): 186-94. PMID:9468189.

Gohn, C.R., Blue, E.K., Sheehan, B.M., Varberg, K.M. and Haneline, L.S. 2016. Mesenchyme Homeobox 2 Enhances Migration of Endothelial Colony Forming Cells Exposed to Intrauterine Diabetes Mellitus. J. Cell. Physiol.: doi:10.1002/jcp.25734. PMID:27966787.

Gorski, D.H., LePage, D.F., Patel, C.V., Copeland, N.G., Jenkins, N.A. and Walsh, K. 1993. Molecular cloning of a diverged homeobox gene that is rapidly down-regulated during the G0/G1 transition in vascular smooth muscle cells. Mol. Cell. Biol. 13(6): 3722-33. PMID:8098844. 
Gorski, D.H. and Leal, A.J. 2003. Inhibition of endothelial cell activation by the homeobox gene Gax. J. Surg. Res. 111(1): 91-9. PMID:12842453.

Gu, W., Shi, X.L. and Roeder, R.G. 1997. Synergistic activation of transcription by CBP and p53. Nature, 387(6635): 819-23. doi:10.1038/42972. PMID:9194564.

Guevara, N.V., Kim, H.S., Antonova, E.I. and Chan, L. 1999. The absence of p53 accelerates atherosclerosis by increasing cell proliferation in vivo. Nat. Med. 5(3): 335-9. doi:10.1038/6585. PMID:10086392.

Han, X., Ling, S., Gan, W., Sun, L., Duan, J. and Xu, J.W. 2012. 2,3,5,4'-tetrahydroxystilbene-2-O-beta-dglucoside ameliorates vascular senescence and improves blood flow involving a mechanism of p53 deacetylation. Atherosclerosis, 225(1): 76-82. doi:10.1016/j.atherosclerosis.2012.08.011. PMID:22981429.

Harkema, L., Youssef, S.A. and de Bruin, A. 2016. Pathology of Mouse Models of Accelerated Aging. Vet. Pathol. 53(2): 366-89. doi:10.1177/0300985815625169. PMID:26864891.

Hastings, R., Qureshi, M., Verma, R., Lacy, P.S. and Williams, B. 2004. Telomere attrition and accumulation of senescent cells in cultured human endothelial cells. Cell Prolif. 37(4): 317-24. doi:10.1111/j.1365-2184.2004.00315.x. PMID:15245567.

Hayflick, L. and Moorhead, P.S. 1961. The serial cultivation of human diploid cell strains. Exp. Cell Res. 25: 585-621. PMID:13905658.

Hayflick, L. 1965. The Limited in Vitro Lifetime of Human Diploid Cell Strains. Exp. Cell Res. 37: 614-36. PMID:14315085.

Hoffmann, J., Haendeler, J., Aicher, A., Rossig, L., Vasa, M., Zeiher, A.M., et al. 2001. Aging enhances the sensitivity of endothelial cells toward apoptotic stimuli: important role of nitric oxide. Circ. Res. 89(8): 709-15. PMID:11597994. 
Hollstein, M., Sidransky, D., Vogelstein, B. and Harris, C.C. 1991. p53 mutations in human cancers. Science, 253(5015): 49-53. PMID:1905840.

Howitz, K.T., Bitterman, K.J., Cohen, H.Y., Lamming, D.W., Lavu, S., Wood, J.G., et al. 2003. Small molecule activators of sirtuins extend Saccharomyces cerevisiae lifespan. Nature, 425(6954): 1916. doi:10.1038/nature01960. PMID:12939617.

Huang, P.L., Huang, Z., Mashimo, H., Bloch, K.D., Moskowitz, M.A., Bevan, J.A., et al. 1995. Hypertension in mice lacking the gene for endothelial nitric oxide synthase. Nature, 377(6546): 239-42. doi:10.1038/377239a0. PMID:7545787.

Ikeda, Y., Kumagai, H., Motozawa, Y., Suzuki, J., Akazawa, H. and Komuro, I. 2016. Understanding Vascular Diseases: Lessons From Premature Aging Syndromes. Can. J. Cardiol. 32(5): 650-8. doi:10.1016/j.cjca.2015.12.003. PMID:26948039.

Karantzoulis-Fegaras, F., Antoniou, H., Lai, S.L., Kulkarni, G., D'Abreo, C., Wong, G.K., et al. 1999. Characterization of the human endothelial nitric-oxide synthase promoter. J. Biol. Chem. 274(5): 3076-93. PMID:9915847.

Koks, S., Dogan, S., Tuna, B.G., Gonzalez-Navarro, H., Potter, P. and Vandenbroucke, R.E. 2016. Mouse models of ageing and their relevance to disease. Mech. Ageing Dev. 160: 41-53. doi:10.1016/j.mad.2016.10.001. PMID:27717883.

Kolluru, G.K., Siamwala, J.H. and Chatterjee, S. 2010. eNOS phosphorylation in health and disease. Biochimie, 92(9): 1186-98. doi:10.1016/j.biochi.2010.03.020. PMID:20363286.

Kovacic, J.C., Moreno, P., Nabel, E.G., Hachinski, V. and Fuster, V. 2011. Cellular senescence, vascular disease, and aging: part 2 of a 2-part review: clinical vascular disease in the elderly. Circulation, 123(17): 1900-10. doi:10.1161/CIRCULATIONAHA.110.009118. PMID:21537006. 
Krishnamurthy, J., Torrice, C., Ramsey, M.R., Kovalev, G.I., Al-Regaiey, K., Su, L., et al. 2004. Ink4a/Arf expression is a biomarker of aging. J. Clin. Invest. 114(9): 1299-307. doi:10.1172/JCI22475. PMID:15520862.

Kuhlencordt, P.J., Gyurko, R., Han, F., Scherrer-Crosbie, M., Aretz, T.H., Hajjar, R., et al. 2001. Accelerated atherosclerosis, aortic aneurysm formation, and ischemic heart disease in apolipoprotein E/endothelial nitric oxide synthase double-knockout mice. Circulation, 104(4): 44854. PMID:11468208.

Kumar, A., Kim, C.S., Hoffman, T.A., Naqvi, A., Dericco, J., Jung, S.B., et al. 2011. p53 impairs endothelial function by transcriptionally repressing Kruppel-Like Factor 2. Arterioscler. Thromb. Vasc. Biol. 31(1): 133-41. doi:10.1161/ATVBAHA.110.215061. PMID:20947822.

Lee, A.C., Fenster, B.E., Ito, H., Takeda, K., Bae, N.S., Hirai, T., et al. 1999. Ras proteins induce senescence by altering the intracellular levels of reactive oxygen species. J. Biol. Chem. 274(12): 7936-40. PMID:10075689.

Lin, S.J., Kaeberlein, M., Andalis, A.A., Sturtz, L.A., Defossez, P.A., Culotta, V.C., et al. 2002. Calorie restriction extends Saccharomyces cerevisiae lifespan by increasing respiration. Nature, 418(6895): 344-8. doi:10.1038/nature00829. PMID:12124627.

Lombard, D.B., Beard, C., Johnson, B., Marciniak, R.A., Dausman, J., Bronson, R., et al. 2000. Mutations in the WRN gene in mice accelerate mortality in a p53-null background. Mol. Cell. Biol. 20(9): 3286-91. PMID:10757812.

Luo, J., Nikolaev, A.Y., Imai, S., Chen, D., Su, F., Shiloh, A., et al. 2001. Negative control of p53 by Sir2alpha promotes cell survival under stress. Cell, 107(2): 137-48. PMID:11672522.

Mackay, J.M., G. 2004. The Atlas of Heart Disease and Stroke: World Health Organization.: 112 p. 
Maier, B., Gluba, W., Bernier, B., Turner, T., Mohammad, K., Guise, T., et al. 2004. Modulation of mammalian life span by the short isoform of p53. Genes Dev. 18(3): 306-19. doi:10.1101/gad.1162404. PMID:14871929.

Maillard, L., Van Belle, E., Smith, R.C., Le Roux, A., Denefle, P., Steg, G., et al. 1997. Percutaneous delivery of the gax gene inhibits vessel stenosis in a rabbit model of balloon angioplasty. Cardiovasc. Res. 35(3): 536-46. PMID:9415299.

Mankoo, B.S., Skuntz, S., Harrigan, I., Grigorieva, E., Candia, A., Wright, C.V., et al. 2003. The concerted action of Meox homeobox genes is required upstream of genetic pathways essential for the formation, patterning and differentiation of somites. Development, 130(19): 4655-64. doi:10.1242/dev.00687. PMID:12925591.

Markmann, A., Rauterberg, J., Vischer, P., Robenek, H., Echtermeyer, F., Will, H., et al. 2003. Expression of transcription factors and matrix genes in response to serum stimulus in vascular smooth muscle cells. Eur. J. Cell Biol. 82(3): 119-29. doi:10.1078/0171-9335-00309. PMID:12691261.

Matsumoto, T., Baker, D.J., d'Uscio, L.V., Mozammel, G., Katusic, Z.S. and van Deursen, J.M. 2007. Aging-associated vascular phenotype in mutant mice with low levels of BubR1. Stroke, 38(3): 1050-6. doi:10.1161/01.STR.0000257967.86132.01. PMID:17272762.

Matsushita, H., Chang, E., Glassford, A.J., Cooke, J.P., Chiu, C.P. and Tsao, P.S. 2001. eNOS activity is reduced in senescent human endothelial cells: Preservation by hTERT immortalization. Circ. Res. 89(9): 793-8. PMID:11679409.

McClintock, D., Ratner, D., Lokuge, M., Owens, D.M., Gordon, L.B., Collins, F.S., et al. 2007. The mutant form of lamin A that causes Hutchinson-Gilford progeria is a biomarker of cellular aging in human skin. PLoS One, 2(12): e1269. doi:10.1371/journal.pone.0001269. PMID:18060063. 
Meier, U.T. 2005. The many facets of H/ACA ribonucleoproteins. Chromosoma, 114(1): 1-14. doi:10.1007/s00412-005-0333-9. PMID:15770508.

Meyrelles, S.S., Peotta, V.A., Pereira, T.M. and Vasquez, E.C. 2011. Endothelial dysfunction in the apolipoprotein E-deficient mouse: insights into the influence of diet, gender and aging. Lipids Health Dis. 10: 211. doi:10.1186/1476-511X-10-211. PMID:22082357.

Minamino, T., Miyauchi, H., Yoshida, T., Ishida, Y., Yoshida, H. and Komuro, I. 2002. Endothelial cell senescence in human atherosclerosis: role of telomere in endothelial dysfunction. Circulation, 105(13): 1541-4. PMID:11927518.

Minamino, T., Yoshida, T., Tateno, K., Miyauchi, H., Zou, Y., Toko, H., et al. 2003. Ras induces vascular smooth muscle cell senescence and inflammation in human atherosclerosis. Circulation, 108(18): 2264-9. doi:10.1161/01.CIR.0000093274.82929.22. PMID:14557365.

Mitchell, J.R., Wood, E. and Collins, K. 1999. A telomerase component is defective in the human disease dyskeratosis congenita. Nature, 402(6761): 551-5. doi:10.1038/990141. PMID:10591218.

Moiseeva, O., Mallette, F.A., Mukhopadhyay, U.K., Moores, A. and Ferbeyre, G. 2006. DNA damage signaling and p53-dependent senescence after prolonged beta-interferon stimulation. Mol. Biol. Cell, 17(4): 1583-92. doi:10.1091/mbc.E05-09-0858. PMID:16436515.

Mortensen, K., Skouv, J., Hougaard, D.M. and Larsson, L.I. 1999. Endogenous endothelial cell nitricoxide synthase modulates apoptosis in cultured breast cancer cells and is transcriptionally regulated by p53. J. Biol. Chem. 274(53): 37679-84. PMID:10608825.

Narita, M., Nunez, S., Heard, E., Narita, M., Lin, A.W., Hearn, S.A., et al. 2003. Rb-mediated heterochromatin formation and silencing of E2F target genes during cellular senescence. Cell, 113(6): 703-16. PMID:12809602. 
Navarro, C.L., Cau, P. and Levy, N. 2006. Molecular bases of progeroid syndromes. Hum. Mol. Genet. 15 Spec No 2: R151-61. doi:10.1093/hmg/ddl214. PMID:16987878.

Novella, S., Dantas, A.P., Segarra, G., Vidal-Gomez, X., Mompeon, A., Garabito, M., et al. 2013. Agingrelated endothelial dysfunction in the aorta from female senescence-accelerated mice is associated with decreased nitric oxide synthase expression. Exp. Gerontol. 48(11): 1329-37. doi:10.1016/j.exger.2013.08.003. PMID:23948180.

Orimo, M., Minamino, T., Miyauchi, H., Tateno, K., Okada, S., Moriya, J., et al. 2009. Protective role of SIRT1 in diabetic vascular dysfunction. Arterioscler. Thromb. Vasc. Biol. 29(6): 889-94. doi:10.1161/ATVBAHA.109.185694. PMID:19286634.

Ota, H., Akishita, M., Eto, M., lijima, K., Kaneki, M. and Ouchi, Y. 2007. Sirt1 modulates premature senescence-like phenotype in human endothelial cells. J. Mol. Cell. Cardiol. 43(5): 571-9. doi:10.1016/j.yjmcc.2007.08.008. PMID:17916362.

Ota, H., Akishita, M., Akiyoshi, T., Kahyo, T., Setou, M., Ogawa, S., et al. 2012. Testosterone deficiency accelerates neuronal and vascular aging of SAMP8 mice: protective role of eNOS and SIRT1. PLoS One, 7(1): e29598. doi:10.1371/journal.pone.0029598. PMID:22238626.

Patel, S., Leal, A.D. and Gorski, D.H. 2005. The homeobox gene Gax inhibits angiogenesis through inhibition of nuclear factor-kappaB-dependent endothelial cell gene expression. Cancer Res. 65(4): 1414-24. doi:10.1158/0008-5472.CAN-04-3431. PMID:15735029.

Pendas, A.M., Zhou, Z., Cadinanos, J., Freije, J.M., Wang, J., Hultenby, K., et al. 2002. Defective prelamin A processing and muscular and adipocyte alterations in Zmpste24 metalloproteinasedeficient mice. Nat. Genet. 31(1): 94-9. doi:10.1038/ng871. PMID:11923874. 
Perlman, H., Sata, M., Le Roux, A., Sedlak, T.W., Branellec, D. and Walsh, K. 1998. Bax-mediated cell death by the Gax homeoprotein requires mitogen activation but is independent of cell cycle activity. EMBO J. 17(13): 3576-86. doi:10.1093/emboj/17.13.3576. PMID:9649428.

Perlman, H., Luo, Z., Krasinski, K., Le Roux, A., Mahfoudi, A., Smith, R.C., et al. 1999. Adenovirusmediated delivery of the Gax transcription factor to rat carotid arteries inhibits smooth muscle proliferation and induces apoptosis. Gene Ther. 6(5): 758-63. doi:10.1038/sj.gt.3300893. PMID:10505098.

Plasilova, M., Chattopadhyay, C., Ghosh, A., Wenzel, F., Demougin, P., Noppen, C., et al. 2011. Discordant gene expression signatures and related phenotypic differences in lamin A- and A/Crelated Hutchinson-Gilford progeria syndrome (HGPS). PLoS One, 6(6): e21433. doi:10.1371/journal.pone.0021433. PMID:21738662.

Pogacic, V., Dragon, F. and Filipowicz, W. 2000. Human H/ACA small nucleolar RNPs and telomerase share evolutionarily conserved proteins NHP2 and NOP10. Mol. Cell. Biol. 20(23): 9028-40. PMID:11074001.

Potente, M., Urbich, C., Sasaki, K., Hofmann, W.K., Heeschen, C., Aicher, A., et al. 2005. Involvement of Foxo transcription factors in angiogenesis and postnatal neovascularization. J. Clin. Invest. 115(9): 2382-92. doi:10.1172/JCI23126. PMID:16100571.

Qian, J. and Fulton, D. 2013. Post-translational regulation of endothelial nitric oxide synthase in vascular endothelium. Front. Physiol. 4: 347. doi:10.3389/fphys.2013.00347. PMID:24379783.

Reed, A.L., Tanaka, A., Sorescu, D., Liu, H., Jeong, E.M., Sturdy, M., et al. 2011. Diastolic dysfunction is associated with cardiac fibrosis in the senescence-accelerated mouse. Am. J. Physiol.: Heart Circ. Physiol. 301(3): H824-31. doi:10.1152/ajpheart.00407.2010. PMID:21724869. 
Roh, D.S., Du, Y., Gabriele, M.L., Robinson, A.R., Niedernhofer, L.J. and Funderburgh, J.L. 2013. Agerelated dystrophic changes in corneal endothelium from DNA repair-deficient mice. Aging Cell, 12(6): 1122-31. doi:10.1111/acel.12143. PMID:23927039.

Rovelet-Lecrux, A., Legallic, S., Wallon, D., Flaman, J.M., Martinaud, O., Bombois, S., et al. 2012. A genome-wide study reveals rare CNVs exclusive to extreme phenotypes of Alzheimer disease. Eur. J. Hum. Genet. 20(6): 613-7. doi:10.1038/ejhg.2011.225. PMID:22166940.

Rufini, A., Tucci, P., Celardo, I. and Melino, G. 2013. Senescence and aging: the critical roles of p53. Oncogene, 32(43): 5129-43. doi:10.1038/onc.2012.640. PMID:23416979.

Russell, J.C. and Proctor, S.D. 2006. Small animal models of cardiovascular disease: tools for the study of the roles of metabolic syndrome, dyslipidemia, and atherosclerosis. Cardiovasc. Pathol. 15(6): 318-30. doi:10.1016/j.carpath.2006.09.001. PMID:17113010.

Sanz-Gonzalez, S.M., Barquin, L., Garcia-Cao, I., Roque, M., Gonzalez, J.M., Fuster, J.J., et al. 2007. Increased p53 gene dosage reduces neointimal thickening induced by mechanical injury but has no effect on native atherosclerosis. Cardiovasc. Res. 75(4): 803-12. doi:10.1016/j.cardiores.2007.05.002. PMID:17570351.

Sato, I., Morita, I., Kaji, K., Ikeda, M., Nagao, M. and Murota, S. 1993. Reduction of nitric oxide producing activity associated with in vitro aging in cultured human umbilical vein endothelial cell. Biochem. Biophys. Res. Commun. 195(2): 1070-6. doi:10.1006/bbrc.1993.2153. PMID:7690550.

Saunders, L.R. and Verdin, E. 2007. Sirtuins: critical regulators at the crossroads between cancer and aging. Oncogene, 26(37): 5489-504. doi:10.1038/sj.onc.1210616. PMID:17694089.

Serrano, M., Lin, A.W., McCurrach, M.E., Beach, D. and Lowe, S.W. 1997. Oncogenic ras provokes premature cell senescence associated with accumulation of p53 and p16INK4a. Cell, 88(5): 593602. PMID:9054499. 
Shesely, E.G., Maeda, N., Kim, H.S., Desai, K.M., Krege, J.H., Laubach, V.E., et al. 1996. Elevated blood pressures in mice lacking endothelial nitric oxide synthase. Proc. Natl. Acad. Sci. U. S. A. 93(23): 13176-81. PMID:8917564.

Smith, R.C., Branellec, D., Gorski, D.H., Guo, K., Perlman, H., Dedieu, J.F., et al. 1997. p21CIP1mediated inhibition of cell proliferation by overexpression of the gax homeodomain gene. Genes Dev. 11(13): 1674-89. PMID:9224717.

Soto, I., Grabowska, W.A., Onos, K.D., Graham, L.C., Jackson, H.M., Simeone, S.N., et al. 2016. Meox2 haploinsufficiency increases neuronal cell loss in a mouse model of Alzheimer's disease. Neurobiol. Aging, 42: 50-60. doi:10.1016/j.neurobiolaging.2016.02.025. PMID:27143421.

Spillare, E.A., Robles, A.I., Wang, X.W., Shen, J.C., Yu, C.E., Schellenberg, G.D., et al. 1999. p53mediated apoptosis is attenuated in Werner syndrome cells. Genes Dev. 13(11): 1355-60. PMID:10364153.

Sumi, D. and Ignarro, L.J. 2003. Estrogen-related receptor alpha 1 up-regulates endothelial nitric oxide synthase expression. Proc. Natl. Acad. Sci. U. S. A. 100(24): 14451-6. doi:10.1073/pnas.2235590100. PMID:14610283.

Tai, S.C., Robb, G.B. and Marsden, P.A. 2004. Endothelial nitric oxide synthase: a new paradigm for gene regulation in the injured blood vessel. Arterioscler. Thromb. Vasc. Biol. 24(3): 405-12. doi:10.1161/01.ATV.0000109171.50229.33. PMID:14656742.

Thum, T., Haverich, A. and Borlak, J. 2000. Cellular dedifferentiation of endothelium is linked to activation and silencing of certain nuclear transcription factors: implications for endothelial dysfunction and vascular biology. FASEB J. 14(5): 740-51. PMID:10744630. 
Tyner, S.D., Venkatachalam, S., Choi, J., Jones, S., Ghebranious, N., Igelmann, H., et al. 2002. p53 mutant mice that display early ageing-associated phenotypes. Nature, 415(6867): 45-53. doi:10.1038/415045a. PMID:11780111.

Uraoka, M., Ikeda, K., Kurimoto-Nakano, R., Nakagawa, Y., Koide, M., Akakabe, Y., et al. 2011. Loss of bcl-2 during the senescence exacerbates the impaired angiogenic functions in endothelial cells by deteriorating the mitochondrial redox state. Hypertension, 58(2): 254-63. doi:10.1161/HYPERTENSIONAHA.111.176701. PMID:21730299.

Vafaie, F., Yin, H., O'Neil, C., Nong, Z., Watson, A., Arpino, J.M., et al. 2014. Collagenase-resistant collagen promotes mouse aging and vascular cell senescence. Aging Cell, 13(1): 121-30. doi:10.1111/acel.12155. PMID:23957394.

Varela, I., Cadinanos, J., Pendas, A.M., Gutierrez-Fernandez, A., Folgueras, A.R., Sanchez, L.M., et al. 2005. Accelerated ageing in mice deficient in Zmpste24 protease is linked to p53 signalling activation. Nature, 437(7058): 564-8. doi:10.1038/nature04019. PMID:16079796.

Varga, R., Eriksson, M., Erdos, M.R., Olive, M., Harten, I., Kolodgie, F., et al. 2006. Progressive vascular smooth muscle cell defects in a mouse model of Hutchinson-Gilford progeria syndrome. Proc. Natl. Acad. Sci. U. S. A. 103(9): 3250-5. doi:10.1073/pnas.0600012103. PMID:16492728.

Vasile, E., Tomita, Y., Brown, L.F., Kocher, O. and Dvorak, H.F. 2001. Differential expression of thymosin beta-10 by early passage and senescent vascular endothelium is modulated by VPF/VEGF: evidence for senescent endothelial cells in vivo at sites of atherosclerosis. FASEB J. 15(2): 458-66. doi:10.1096/fj.00-0051com. PMID:11156961.

Vasquez, E.C., Peotta, V.A., Gava, A.L., Pereira, T.M. and Meyrelles, S.S. 2012. Cardiac and vascular phenotypes in the apolipoprotein E-deficient mouse. J. Biomed. Sci. 19: 22. doi:10.1186/14230127-19-22. PMID:22330242. 
Verstraeten, V.L., Ji, J.Y., Cummings, K.S., Lee, R.T. and Lammerding, J. 2008. Increased mechanosensitivity and nuclear stiffness in Hutchinson-Gilford progeria cells: effects of farnesyltransferase inhibitors. Aging Cell, 7(3): 383-93. doi:10.1111/j.1474-9726.2008.00382.x. PMID:18331619.

Warboys, C.M., de Luca, A., Amini, N., Luong, L., Duckles, H., Hsiao, S., et al. 2014. Disturbed flow promotes endothelial senescence via a p53-dependent pathway. Arterioscler. Thromb. Vasc. Biol. 34(5): 985-95. doi:10.1161/ATVBAHA.114.303415. PMID:24651677.

Weeda, G., Donker, I., de Wit, J., Morreau, H., Janssens, R., Vissers, C.J., et al. 1997. Disruption of mouse ERCC1 results in a novel repair syndrome with growth failure, nuclear abnormalities and senescence. Curr. Biol. 7(6): 427-39. PMID:9197240.

Weir, L., Chen, D., Pastore, C., Isner, J.M. and Walsh, K. 1995. Expression of gax, a growth arrest homeobox gene, is rapidly down-regulated in the rat carotid artery during the proliferative response to balloon injury. J. Biol. Chem. 270(10): 5457-61. PMID:7890661.

Witzenbichler, B., Kureishi, Y., Luo, Z., Le Roux, A., Branellec, D. and Walsh, K. 1999. Regulation of smooth muscle cell migration and integrin expression by the Gax transcription factor. J. Clin. Invest. 104(10): 1469-80. doi:10.1172/JCI7251. PMID:10562309.

Wu, Z., Guo, H., Chow, N., Sallstrom, J., Bell, R.D., Deane, R., et al. 2005. Role of the MEOX2 homeobox gene in neurovascular dysfunction in Alzheimer disease. Nat. Med. 11(9): 959-65. doi:10.1038/nm1287. PMID:16116430.

Yang, W.Y., Petit, T., Thijs, L., Zhang, Z.Y., Jacobs, L., Hara, A., et al. 2015. Coronary risk in relation to genetic variation in MEOX2 and TCF15 in a Flemish population. BMC Genet. 16: 116. doi:10.1186/s12863-015-0272-2. PMID:26428460. 
Yokoyama, M., Okada, S., Nakagomi, A., Moriya, J., Shimizu, I., Nojima, A., et al. 2014. Inhibition of endothelial p53 improves metabolic abnormalities related to dietary obesity. Cell Rep. 7(5): 1691703. doi:10.1016/j.celrep.2014.04.046. PMID:24857662.

Zeng, J.H., Yang, Z., Xu, J., Qiu, M.L. and Lin, K.C. 2006. Down-regulation of the gax gene in smooth muscle cells of the splenic vein of portal hypertension patients. Hepatobiliary Pancreatic Dis. Int. 5(2): 242-5. PMID:16698584. 


\section{List of Figures}

\section{Figure 1: Mechanisms of vascular ageing.}

Activation of multiple interconnected cellular processes (via molecular crosstalk) underlies vascular ageing and the development of disease, including: senescence, EC dysfunction, oxidative stress, inflammation and genomic instability.

\section{Figure 2: Ageing and p53.}

In healthy endothelial cells, activation of p53 through post-translational modifications leads to cellular quiescence. Acetylation of p53 turns it into a more potent transcriptional regulator and the SIRT1 deacetylase moderates the level of p53 activity. In aged vasculature, loss of SIRT1 expression leads to the hyperactivation of $\mathrm{p} 53$ and induction of cellular senescence.

\section{Figure 3: MEOX1 and MEOX2 reduce eNOS expression in human umbilical vein endothelial cells.}

(A) Enrichment map showing the gene ontology gene-sets whose constituent genes are over (red) and under (blue) represented in HUVECs expressing MEOX proteins. The outer and inner node colours represent the enrichment value in MEOX expressing cells as compared to EGFP expressing control cells. The node size reflects the number of genes contained in each gene-set. (B) Heatmap demonstrating selected probe-set expression values from HUVECs transduced with EGFP, MEOX1, MEOX2 or DNA-binding domain mutated MEOX2 ${ }^{\mathrm{Q} 235 \mathrm{E}}$ (Q235E). The expression values for each probeset have been normalized by row. (C) Level of NOS3 mRNA relative to EGFP over-expressing HUVECs. The relative amounts of mRNA were measured by quantitative real-time PCR. $\beta$-actin mRNA expression was used for inter-sample normalization. (D) Representative western blot and 
quantification showing the levels of total eNOS protein in HUVECs expressing MEOX proteins. The intensity of the eNOS band was normalized to the $\alpha$-tubulin loading control. (E) Representative western blot image and quantification showing increased p53 protein in HUVECs over-expressing MEOX proteins. For all experiments, total RNA or protein was isolated from HUVECs 48 hours posttransduction with $250 \mathrm{MOI}$ of adenovirus. ${ }^{*}$ Indicates a statistically significant difference $(p<0.05)$ from EGFP. Error bars represent the standard error of the mean $(n \geq 4)$.

\section{Figure 4: Summary of the role of MEOX2 in vascular dysfunction.}

In endothelial cells, MEOX2 increases $\mathrm{p} 21^{\mathrm{CIP} 1 / \mathrm{WAF} 1}$ and $\mathrm{p} 16^{\mathrm{INK} 4 \mathrm{~A}}$ expression at the transcriptional level and also augments p53 protein expression (by an unknown mechanism), leading to decreased EC proliferation and increased senescence. In addition, MEOX2 represses transcription of the NOS3 gene, which is expected to reduce NO production and thereby promote vasoconstriction. 


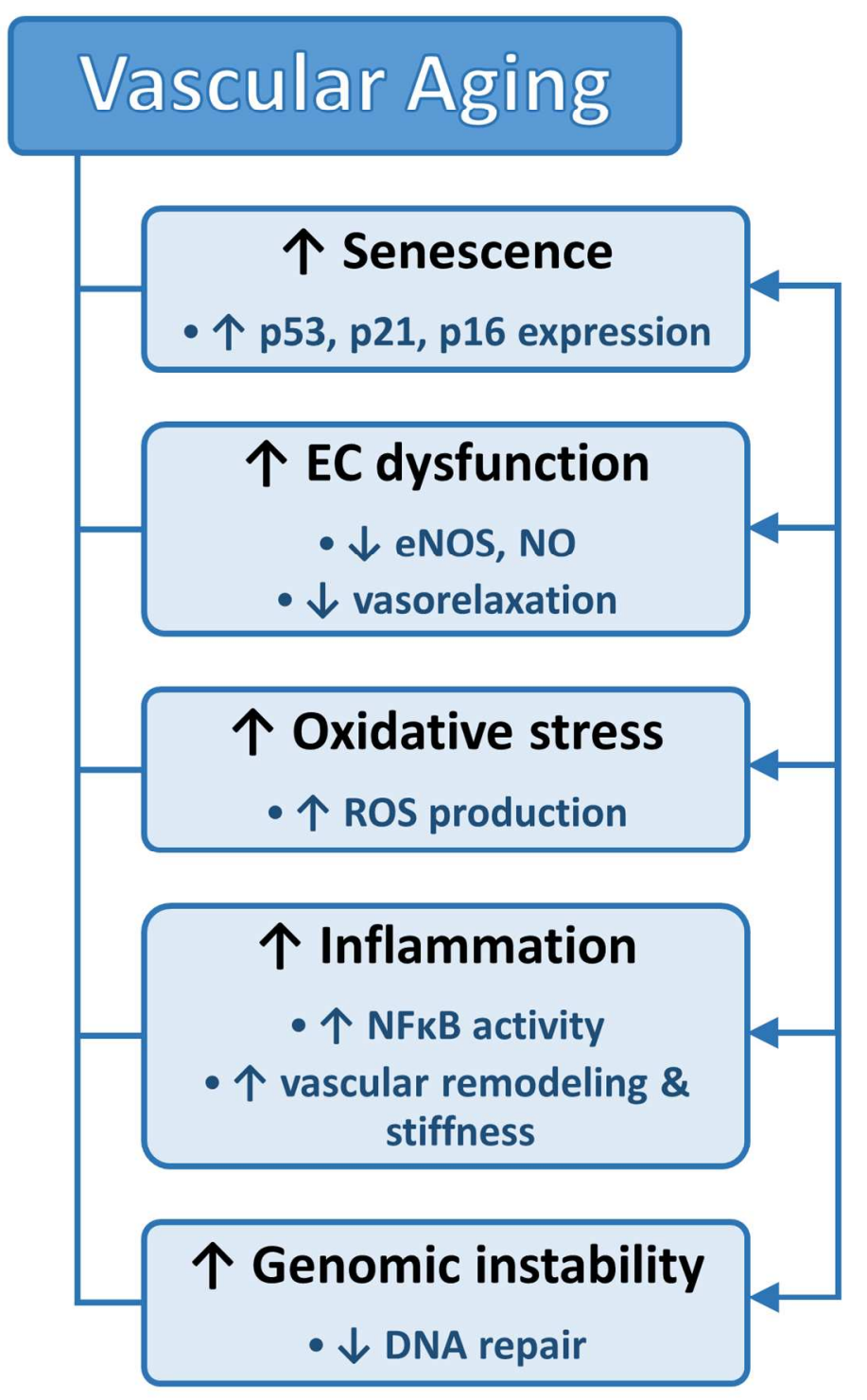

$114 \times 165 \mathrm{~mm}(300 \times 300 \mathrm{DPI})$ 

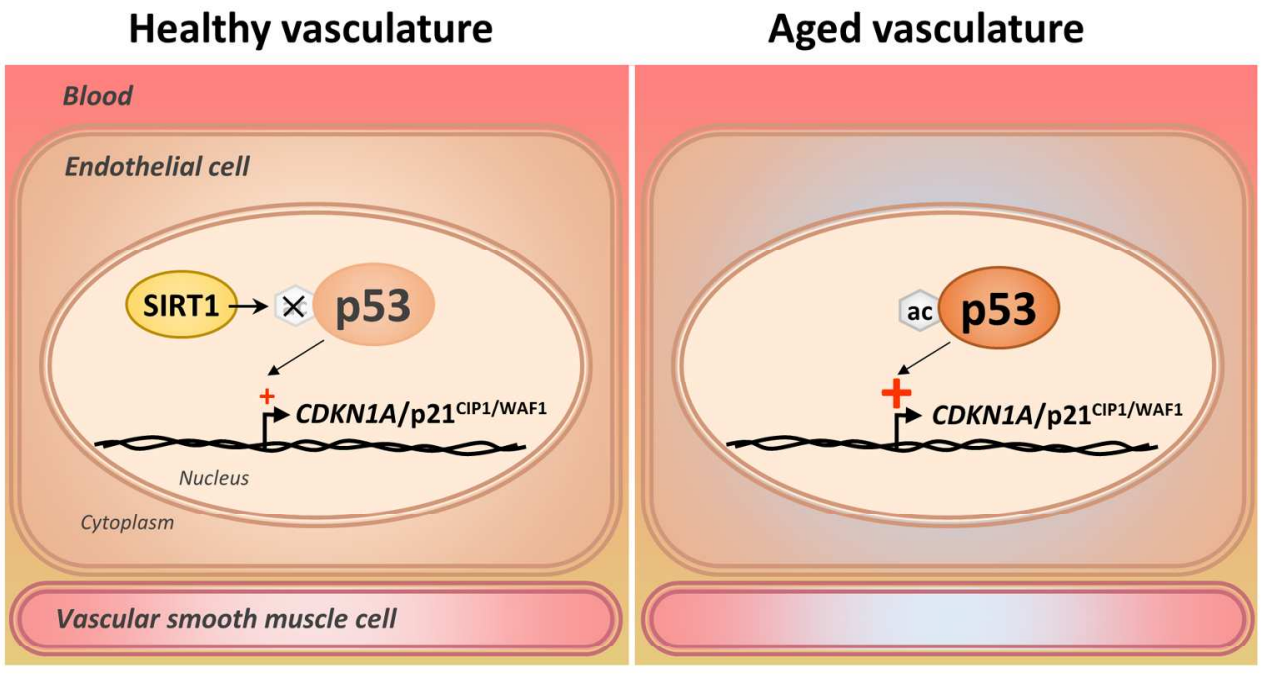

- Low levels of p53 activity

o Resistance to tumorigenesis

- Cell cycle arrest (quiescence)

- Longevity

- High levels of p53 activity o Increased ROS

o DNA damage

- Senescence induction

- Premature aging

$165 \times 116 \mathrm{~mm}(300 \times 300$ DPI $)$ 


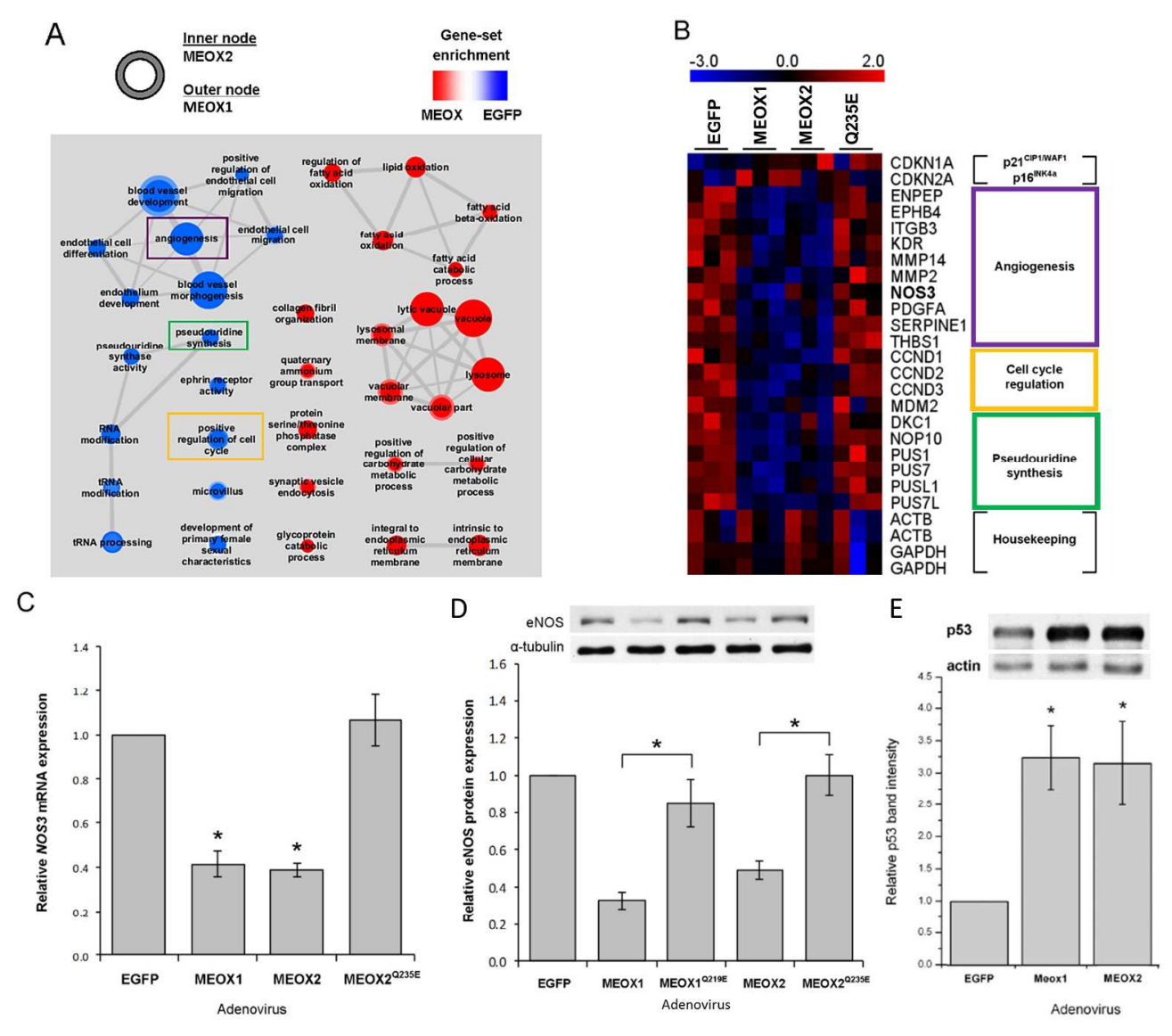

$187 \times 165 \mathrm{~mm}(300 \times 300 \mathrm{DPI})$ 


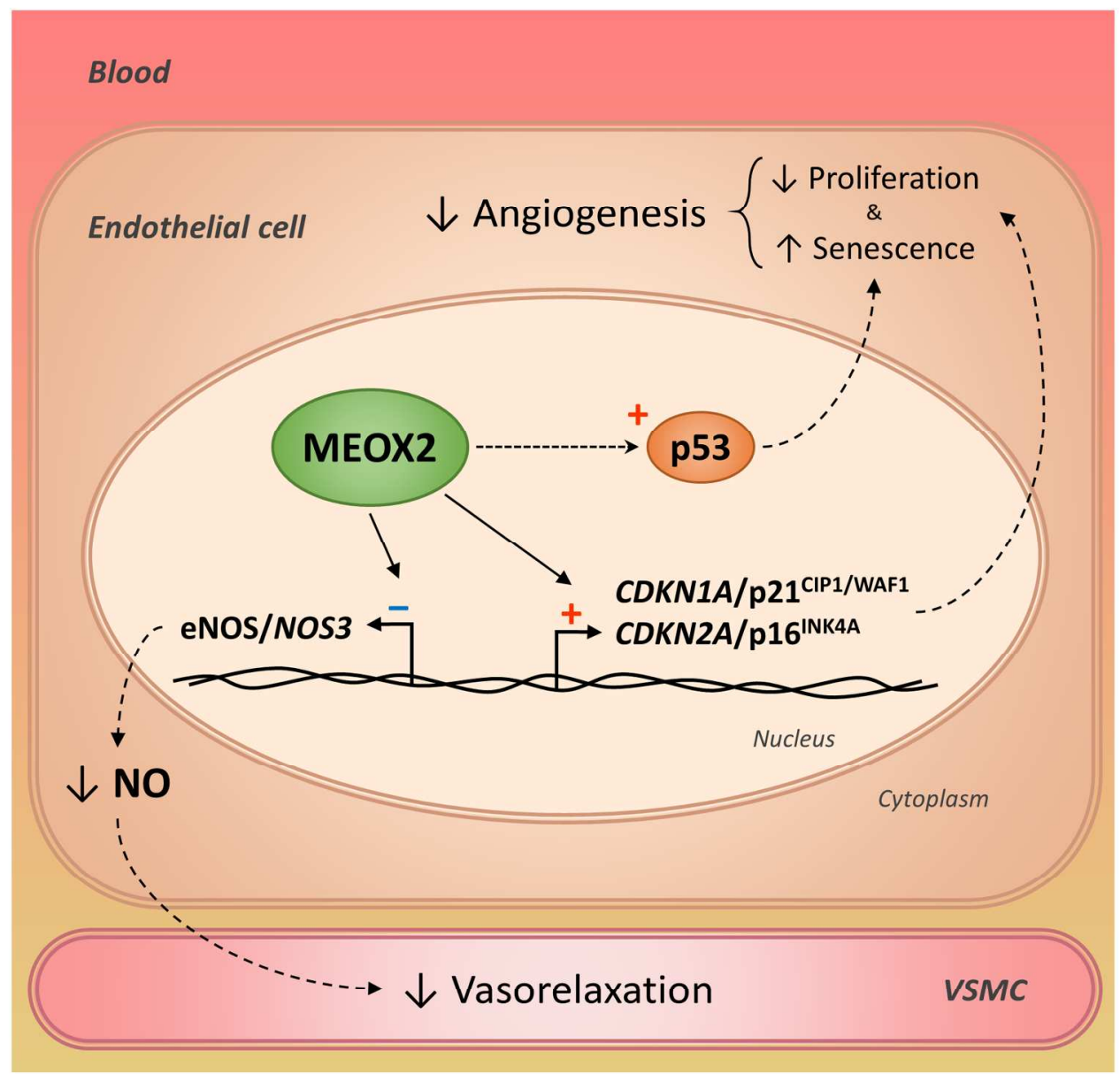

$165 \times 160 \mathrm{~mm}(300 \times 300 \mathrm{DPI})$ 